\title{
TTR
}

Traduction, terminologie, re?daction

\section{Simultaneous interpreters: One ear may be better than two}

\section{Sylvie Lambert}

Volume 2, numéro 1, 1er semestre 1989

Carrefours de la traduction

URI : https://id.erudit.org/iderudit/037040ar

DOI : https://doi.org/10.7202/037040ar

Aller au sommaire du numéro

Éditeur(s)

Association canadienne de traductologie

ISSN

0835-8443 (imprimé)

1708-2188 (numérique)

Découvrir la revue

Citer cet article

Lambert, S. (1989). Simultaneous interpreters: One ear may be better than two. TTR, 2(1), 153-162. https://doi.org/10.7202/037040ar d'utilisation que vous pouvez consulter en ligne.

https://apropos.erudit.org/fr/usagers/politique-dutilisation/ 


\section{Simultaneous interpreters: One ear may be better than two}

\section{Sylvie Lambert}

Experienced conference interpreters tend to interpret with one headphone placed squarely on one ear and with the other headphone either slightly or completely off the other ear. To explain these proclivities, some claim that the headphone set feels too tight if both ears remain covered; others say that releasing one ear in this fashion enables them to monitor their output for both content and volume while interpreting; others simply state that they «feel better" or «hear better» under such circumstances. Whatever the case may be, only a handful of studies have examined simultaneous interpreters' headphone habits. This paper, therefore, purports to review some of the recent laterality studies carried out on conference interpreters when asked to shadow, interpret simultaneously and perform certain finger-tapping exercises when processing information presented to their left ear, their right ear, and both ears.

Lawson (1967) made a brief reference to the use of one ear versus the other when interpreting simultaneously, but the main concern of her paper was selective attention to discourse, in other words, the ability to attend selectively to some aspects of verbal input while rejecting others, rather than the laterality of the more proficient ear.

In a description of the tasks, procedures, and environment of simultaneous interpreters, Parsons (1975) queried her subjects' use of headphones and reported that "four out of five said they normally kept an earphone off one ear, either completely or a little. Two said it was the right ear, one specified the left ear, one reported alternating, and one did not respond.»

More recently, a questionnaire designed for simultaneous interpreters (Lambert and Lambert, 1985) asked specific questions as to gender, handedness (based on Oldfield's, 1971, Edinburgh Handedness Inventory), mother-tongue, dominant language (L1), second-language 
(L2), age of acquisition of L2, ear preference when speaking on the telephone, and ear preference when interpreting.

The fact that so little is mentioned about the use of one ear versus the other when examining simultaneous interpretation is somewhat surprising, given that relying on one ear over the other is of considerable importance. The choice, albeit an unconscious one, is directly related to the processing of information via the left or the right hemisphere of the brain (Broadbent, 1954; Kimura, 1963). Lately, functional asymmetry of the cerebral hemispheres (i.e. processing information via one hemisphere as opposed to the other) has been receiving more and more attention and converging evidence implicates left hemisphere preference in verbal performance and right hemisphere preference for non-verbal performance among male, right-handed unilinguals (for extensive reviews, see Vaid, 1983; Hall and Lambert, 1988).

Of significant importance to conference interpreters, however, is the fact that a growing body of research now seems to suggest that the brains of individuals who speak more than one language may be functionally different from those of unilinguals (Sussman, Franklin, and Simon, 1982; Vaid, 1983). Monolingual children, for example, show highly asymmetric lateralization effects in favour of left hemisphere superiority, whereas bilingual children revealed tendencies towards more symmetric hemispheric language laterality because the right hemisphere was more prominently brought into play (for extensive reviews, see Hall and Lambert, 1988; Vaid, 1983; Vaid and Genesee, 1980).

Although the literature on the functional asymmetry of cerebral hemispheres may seem either irrelevant or baffling to the interpretation profession at first glance, interpreter-trainers and cognitive psychologists cannot afford to ignore this informative research that addresses the possibility that distinct lateralization patterns may characterize individuals who speak more than one language and, by extension, both translators and interpreters. This information, therefore, could be of significant importance and interest in the selection and subsequent training of simultaneous interpreters.

\section{Earedness and shadowing}

One study carried out at the University of Ottawa (Kraushaar and Lambert, 1987) set out to compare trainee-interpreters' shadowing ability in both their first and second languages when shadowing verbal stimuli presented to either one ear or the other. Shadowing is a paced, auditory tracking task which involves the immediate vocalization of auditorily presented stimuli, that is, word-for-word repetition, in the same language, of a message presented to a subject through a set of 
headphones. The shadowing technique has often been used by cognitive psychologists as a means of studying selective attention in humans: briefly, subjects hear one message in one ear, and a different message in the other ear, and are asked to ignore one message while attending to the other for subsequent recall. But shadowing is also frequently used in various schools of interpretation as part of the training method with beginning interpreters who first need to learn to listen and speak simultaneously in the same language before beginning to interpret from one language to another.

Although most interpreters are familiar with the shadowing technique, it is important to mention at this stage that Norman (1976) distinguishes two types of shadowing, namely phonemic shadowing, where subjects repeat each sound as they hear it, without waiting for the completion of a propositional phrase or "chunk», or even a completed word, so that the shadower remains right «on top of" the speaker. The other form of shadowing is known as phrase shadowing, where subjects repeat the speech at longer latencies, more precisely from 250 milliseconds upwards, and where shadowers wait for a semantic chunk before vocalizing in the same way that a simultaneous interpreter would lag behind the original speaker. In a study by Chistovich, Aliakrinskii and Abilian (1960), subjects who shadowed at longer latencies, in other words, with a greater lag, showed superior recall of the shadowed material. It was hypothesized that they used this lag to analyze the semantic content of the material as opposed to those who shadowed without understanding. In the Kraushaar and Lambert experiment, subjects were asked to shadow phonemically so as to minimize the lag as much as possible thus decreasing their chances of analyzing the content of the incoming message, and reducing to a minimum any interfering variables such as deeper forms of semantic processing.

If we are to assume that an interpreter removes one headphone from one ear, for whatever reason, the questions that come to mind are whether or not the same ear is consistently released. Consistent releasing of one ear as opposed to the other could shed light on certain cognitive processes involved during both shadowing and simultaneous interpretation. Other variables such as the subjects' handedness, telephone habits (i.e. whether the receiver is consistently placed on the same ear, and whether this ear is the preferred ear during simultaneous interpretation), language dominance and language employed during shadowing ( $\mathrm{L} 1$ as opposed to $\mathrm{L} 2$ ) were also examined in this study.

Results indicated that both Francophone and Anglophone shadowers made proportionally more shadowing errors in L2 than in L1. Types of shadowing errors included inversions, contractions, substitutions, hesitations, repetitions, stumbling, mispronunciations, additions 
and omissions. (Specific examples and the detailed procedure of the experiment are given elsewhere. See Kraushaar and Lambert, 1987).

Subjects were also broken down into early vs. late bilinguals, depending on the age at which they had acquired their second language. Although the sample sizes were too small to obtain any statistical significance, certain interesting trends did emerge: results suggested that late bilinguals made fewer errors in L1, irrespective of ear of input, than early bilinguals, who made nearly twice as many errors. However, late bilinguals tripled the number of errors in L2, irrespective of ear of input, while early bilinguals only doubled theirs.

There was also a tendency for late bilinguals to process L1 material more effectively through the right ear (i.e. via the left hemisphere) whereas early bilinguals exhibited no such ear preference. Instead, early bilinguals scored somewhat better on L2 material when shadowing material presented to their left ear.

In summary, when shadowing in one's L2, subjects are free to process the incoming information through either or both ears. However, there is a suggestion that when shadowing one's mother tongue, $\mathrm{Ll}$, subjects process incoming speeches better through the right ear.

The fact that processing incoming information through one ear versus the other may influence performance for a relatively "shallow" task such as shadowing, in the sense that less semantic processing is involved as compared to simultaneous interpretation, raises the question as to what the results would be following deeper and more meaningful tasks such as simultaneous interpretation. In other words, if the performance of a simultaneous interpreter is significantly affected by some interaction of the ear of reception and the language of input (i.e. working from or to one's L1), then a comprehensive study of such factors might help us not only understand the fascinating process of interpretation but might also entail certain interpreter-training techniques, even possible modifications to headphone design. To this effect, a subsequent experiment was carried out on earedness and simultaneous interpretation.

\section{Earedness and simultaneous interpretation}

Two twelve-minute long speeches taken from Hansards (1984 and 1986) were recorded stereophonically at approximately 110 words per minute. One speech was in French, the other in English, and both were welcoming addresses to visiting Heads-of-State, in other words, made no demands on subjects' knowledge of specialized or technical vocabularies.

Twenty-one subjects from the Ottawa area served as subjects and included both beginning interpreters from the two-year Diploma Pro- 
gramme at Ottawa University who had been interpreting for more than six months, as well as professional interpreters working in Ottawa. The breakdown according to sex and language was as follows: 6 female francophones; 6 female anglophones; 2 male francophones; 7 male anglophones.

Although the detailed method and procedure are provided elsewhere (Lambert, 1988), one important detail deserves some explanation. Since the experimenter wanted to minimize any bias in the results, it was decided that an incidental learning paradigm would be the best solution: in other words, subjects were not informed of the nature of the experiment beforehand, but were simply told that the experiment involved measuring an interpreter's ability to interpret under different working conditions. It was only after the experiment that subjects were informed of the nature of the experiment and that they were asked to complete the Lambert and Lambert questionnaire (1985) to determine earedness, degree of bilinguality and telephone habits.

To this effect, a special custom-made device (Capello Audio of Ottawa) included a dial which enabled the experimenter to shunt the recorded speeches to one ear or to both ears simultaneously without alerting the subject to this fact. However, in a pilot test, subjects felt that they were unable to hear as well when the message was presented to their non-preferred ear, therefore, an amplifier was connected to the source speech so that subjects could manipulate the volume at will, to compensate for any loss.

Each twelve-minute long speech was divided into four threeminute segments. The first segment served as a warm-up and was never evaluated. Following the warm-up, and without any interruption in the speech, the experimenter shunted the next three-minute segment to one of three possible directions:

Condition I: both ears simultaneously

Condition II: right ear only

Condition III: left ear only

To facilitate correction of interpreters' output, all subjects' interpretations were transcribed and matched against the original by two independent judges. Interjudge correlation across 21 subjects was .91 , both judges blind to subjects' conditions and to the experimental hypotheses. Scoring of interpretation protocols was based on data collected by Henri C. Barik (1975). Briefly put, an interpreter's version may depart from the original in three ways: the interpreter may omit some material, add some information, or substitute material, which, if at considerable variance with the original, may constitute a meaning error. A more detailed description of the procedure followed to arrive at such categorizations can be found elsewhere (Barik, 1971). 
Results indicated that right-handed subjects (18 subjects of the 21 were right-handed) made significantly fewer errors when interpreting a message presented to their right hemisphere through their left ear $(\bar{X}=5.54 ; \mathrm{p} \leq .02)$, than to their right ear, or, more arrestingly, to both ears simultaneously.

In other words, subjects made significantly fewer errors when the message was shunted to one ear than to both ears simultaneously (Wilcoxon matched-pairs signed ranks test $W=46$, for $n=21$ ).

If we compare these results with those obtained for shadowing (Kraushaar and Lambert, 1987) which suggested that when shadowing in one's L2, the ear of reception does not appear to matter, be it one ear or both ears, but that when shadowing in one's L1, speech may be better processed when directed to the right ear, results for simultaneous interpretation indicate that when interpreting from $\mathrm{L} 2$ to $\mathrm{L} 1$, right-handed individuals function more efficiently with a left-ear input, and that processing incoming messages through one ear is more effective than through two ears.

The discovery of such a left-ear preference for interpreting verbal information is difficult to reconcile with the dichotic listening literature which clearly suggests that, for right-handed individuals, the right ear (i.e. the left hemisphere) would be chosen over the left ear whenever verbal information is to be processed (Broadbent, 1954; Kimura, 1963). So how do we explain the fact that interpreters performed significantly better when they interpreted via the left ear, or via both ears simultaneously, but not via the right ear?

One possible explanation may lie in the nature of the tasks involved during simultaneous interpretation. Simply put, from a cognitive psychologist's point of view, interpreters are basically involved in two concurrent activities: listening and speaking, or decoding and encoding. Both activities are verbal and hence one would expect a favouring of right-ear-to-left-hemisphere route for both tasks, which may be neurologically impossible. But since the results in the interpretation experiment revealed a marked preference for the left-ear-to-righthemisphere route, it could be that interpreters favour the right-ear-toleft-hemisphere route to monitor their own output. If we are to assume that both decoding and encoding activities cannot be performed simultaneously through the same ear or the same hemisphere, the fact that such a high percentage of interpreters release one headphone may be telling us that interpreters consciously or unconsciously use their left hemisphere (right ear) for what they consider to be the more critical of the two concurrent tasks, namely monitoring his/her own output, and the right hemisphere (left ear) for processing the incoming information. 
These results raise an interesting issue, and one that is amenable to further research: what happens when an interpreter works from $\mathrm{L} 1$ to L2? Will the same ear preference remain? Will the interpreter release the same ear?

A second explanation may be that bilingual subjects make more use of their right hemisphere than monolingual individuals who serve as subjects in most dichotic listening experiments. Of the many factors found in language acquisition histories, the age of onset of bilingualism has provided the least equivocal results in behavioural studies (Genesee, 1977). Bilinguals who acquired their second language at infancy appear to employ a different strategy in processing verbal material than that used by bilinguals who acquired their language later in life. The difference appears to be reflected in the language processing strategy adopted by the two groups: those who became bilingual at infancy or in early childhood appear to use an analytic, semantic approach to verbal material. In contrast, those bilinguals who acquired their second language during adolescence or thereafter tend to adopt a different approach to verbal material, one that relies more on extralinguistic (e.g. physical) features of the linguistic stimuli.

By extension, therefore, it could be that simultaneous interpreters, as bilinguals, employ different strategies in processing verbal material such as using the right hemisphere to a greater extent than, say, monolingual individuals.

\section{Finger-tapping experiments}

There are various ways to study laterality, earedness and hemispheric specialization in humans, ranging from neurosurgical testing by way of sodium amytal injections into the carotid, electroencephalography, to dichotic listening and the dual-task or time-sharing paradigm (Kinsbourne and Cook, 1971). Obviously, dichotic listening and dual-task testing are more amenable for studying simultaneous interpreters. The most recent experimentation on simultaneous interpretation is being carried out by Gran and Fabbro (1988) in Trieste, Italy, and by Schweda-Nicholson (personal communication) at the University of Delaware.

The dual-task or time-share paradigm was developed by Kinsbourne and Cook in 1971 to study cerebral lateralization for some superior cognitive functions such as speech recognition and production. Briefly, the dual-task procedure requires a subject to tap a key as rapidly as possible while simultaneously speaking. This key is connected to a digital counter which records the exact number of finger taps produced by the subject as well as any disruption while doing so.

During the experiment, subjects are instructed to press the key as quickly as possible, first with their right index finger for example, 
(the right hand being controlled by the left hemisphere), then with their left index finger (controlled by the right hemisphere). At the same time, subjects are asked to perform a concurrent verbal task, such as reading out loud, reciting a series of words, shadowing, or interpreting simultaneously. As a control, subjects are also asked to finger tap while remaining silent. The number of taps recorded when the verbal task is present is then compared to the number of taps recorded when the subject is silent, as well as the number of taps produced by the left finger vs. the right finger.

Any disruption in the finger tapping rate or any large discrepancy between the number of finger taps by the left finger compared to the right finger indicates that some type of interference occurred and tells the experimenter which hemisphere was involved during the verbal activity. So by analyzing the degree of interference, known as percentage interference, we obtain the following type of information: in monolingual right-handers, a verbal task causes greater interference on right-hand tapping (left hemisphere) than on left-hand tapping (right hemisphere), a finding which is interpreted as a reflection of the demands made on left-hemisphere processing capacities (Kinsbourne and Cook, 1971; Hicks, 1975).

The same technique has recently been extended to French immersion students (Hall and Lambert, 1988) who also used the dual-task procedure and found significantly greater disruption with right-hand tapping, presumably indicating similarly high levels of left hemisphere involvement.

Taking it one step closer to simultaneous interpretation, Albert and Obler (1978) pointed out that studies should be conducted on cerebral asymmetries during simultaneous interpretation. They suggest that cerebral lateralization during simultaneous interpretation from $\mathrm{L} 1$ to L2 may be different than interpretation from L2 to L1. To this effect, experiments were conducted by Laura Gran and Franco Fabbro $(1987 ; 1988)$ at the University of Trieste. Their results indicated that there were no statistically different differences displayed by the two hands of their subjects which suggests that there is concurrent participation of both cerebral hemispheres in the linguistic functions involved in simultaneous interpretation.

But Gran and Fabbro (1988) did find that fourth-year students, while maintaining left-hemisphere dominance for their mother-tongue (Italian), showed significant right-hemisphere superiority for English as compared to first-year students and monolinguals. Gran adds that if one considers the highly demanding task of simultaneous interpretation, it emerges that a bilateral cerebral representation of languages enhances the efficiency and, possibly, the resistance to fatigue among professional interpreters. 
Given the unexpected results found in Lambert's (1988) experiment on earedness and simultaneous interpretation, whereby righthanded interpreters performed better when processing information via one ear than via two ears, and that the preferred ear was overwhelmingly the left ear, an extension of the finger-tapping experiment is warranted to confirm the earlier findings.

To this effect, interpreter-subjects will be asked to interpret under the same three conditions, namely via the left ear, then the right ear, followed by both ears, while simultaneously tapping a key as quickly as possible with the left index finger, followed by the right index finger. It is hoped that these results will corroborate the unexpected finding that for simultaneous interpretation one ear may be better than two.

University of Ottawa

\section{References}

AlBert, M.L. and L. K. Obler (1978). The Bilingual Brain: Neuropsychological and Neurolinguistic Aspects of Bilingualism. New York, London, Academic Press.

BARIK, H.C. (1971). «A description of various types of omissions, additions and errors of translation encountered in simultaneous interpretation». Meta, 16, p. 199.

(1975). «Simultaneous interpretation: qualitative and linguistic data». Language and Speech, 18, pp. 272-297.

BroadBent, D.E. (1954). "The role of auditory localization in attention and memory span». Journal of Experimental Psychology, 47, pp. 191-196.

Chistovitch, L.A., A.A. Aliakrinskii, and V. A. Abilian (1960). «Time delays in speech perception». Questions of Psychology, 1, pp. 64-70.

Genesee, F. (1977). «Summary and discussion». In P.A. Hornby, ed. Bilingualism: Psychological, Social and Educational Implications. New York, Academic Press, pp. 147-164.

GraN, L., and F. Fabbro (1987). «Cerebral lateralization in simultaneous interpreting». Proceedings of the Annual American Translators' Association (ATA) Conference. Albuquerque, New Mexico, October 8-11.

(1988). "The role of neuroscience in the teaching of interpretation». The Interpreters' Newsletter, 1, September 1988, University of Trieste, pp. 23-41.

HaLL, G., and W. E. Lambert (1988). «French immersion and hemispheric language processing: a dual-task study». Canadian Journal of Behavioural Science, 20, pp. 1-14. 
HANSARD (1984; 1986). «House of Commons Debates; Official Report», (Hansard, vol. 128, no. 204, First Session, 33rd Parliament, Tuesday, May 8, 1984; Monday, January 13, 1986). Speeches welcoming Prime Minister Nakasone of Japan and Mexican President, Miguel de la Madrid Hurtado.

Hicks, R., (1975). «Intra-hemispheric response competition between vocal and unimanual performance in normal adult human males». Journal of Comparative Physiological Psychology, 89, pp. 50-60.

KIMURA, D. (1963). «Speech lateralization in young children as determined by an auditory test». Journal of Comparative Physiological Psychology, 56, pp. 899-902.

KInSBOURNE, M., and J. Cook (1971). «Generalized and lateralized effects of concurrent verbalization on a unimanual skill». Quarterly Journal of Experimental Psychology, 23, pp. 341-345.

KRAUSHAAR, B., and S. Lambert (1987). «Shadowing proficiency according to ear of input and type of bilinguality". Bulletin of the Canadian Association of Applied Linguistics, Spring, vol. 9, no. 1, pp. 17-31.

LAMBERT, S. (1988). «Proficiency of interpretation according to ear of input information», Brain and Language (in press).

LAMBERT, S., and W. E. Lambert (1985). «Psysiology: a questionnaire». Meta, 30,1, pp. 68-72.

LAWsON, E.A. (1967). «Attention and simultaneous translation.» Language and Speech, 10, pp. 29-35.

Norman, D.A. (1976). Memory and Attention, New York, Wiley.

OLDFIELD, R.C. (1971). "The assessment and analysis of handedness. The Edinburgh Inventory". Neuropsychologia, 9, pp. 97-113.

PARSONS, H.M. (1975). «Human factors approach to simultaneous interpretation». Language, Interpretation and Communication. D. Gerver and W.H. Sinaiko, eds., Plenum Press.

Sussman, H., P. Franklin and T. Simon (1982). «Bilingual Speech: Bilateral Control?» Brain and Language, 15, pp. 125-142.

VAID, J. (1983). «Bilingualism and brain lateralization". Language Functions and Brain Organization. S.J. Segalowitz, ed. New York, Academic Press.

VAID, J., and F. Genesee (1980). «Neuropsychological approaches to bilingualism». Canadian Journal of Psychology, 34, 4, pp. 417-445. 